\title{
BUD VARIATIONS IN SUGAR CANE
}

\author{
Carl S. Pomeroy \\ Burean of Plant Industry, Unitcd States Department of Agriculture, \\ Riverside, Cal.
}

$\mathrm{T}^{\mathrm{H}}$

HE occurrence of bud mutations in cultivated plants has long been known and the commercial value of many such forms has been recognized. Several hundred bud varieties of fruits, flowers, and other plants grown for their economic or ornamental value are in more or less general cultivation at the present time. As examples of such varieties mentioned may be made of the Washington Navel orange, the Pima cotton and several forms of the Nephrolepis fern.

A recent study of plant varieties known to have originated as bud mutations disclosed the importance of such forms in the development of the cane sugar industry. The following account of the bud origin of several sugar-cane varieties is presented in the hope that it may reach a wider distribution among students of genetics than was secured by the publications reviewed, i. $e .:$ (1) The West Indian Bulletin, vol. 2, No. 3 (1901 or 1902), pp. 216-223, "Bud Variation in the Sugar Cane."

"Cane Sugar," Noel Deerr, London, 1911, pp. 23-38.

Anyone especially interested in this subject should consult these articles, as Mr. Deerr's book has colored plates of several of the bud-varieties described and the figures reproduced herewith are shown in color in the West Indian Bulletin.

Sugar cane (Saccharum officinarum Linn.) is one of the most important of our economic crops, and yet the development of the scientific study of it dates back but little over a generation. This is probably due largely to the con- finement of its cultivation to widely scattered districts, most of which are remote from the older centers of civilization and to the decentralized development of the industry.

Previous to 1885 it was generally believed that the flowers of the sugar cane were infertile, notwithstanding that there are severàl earlier recorded instances of the occurrence of seed. All propagation was by the planting of joints of the stalks. and it is believed that practically all the varieties in commercial cultivation up to within the last twenty-five years originated as bud variations.

Since the rediscovery of the fertility of the flowers of the sugar cane, which was made independently by Soltwede! in Java in 1888, and by Harrison and Bovell in Barbados in 1889, valuable varieties have been developed as seedlings. Commercial propagations are still made entirely by planting pieces of the stalk. Seed propagation is only practiced in the search for new varieties, as seedlings show the characters of their parents in but very slight degrees.

\section{VARIATIONS FROM STRIPED VARIETIES}

The earliest recorded instance of bud variation in the sugar cane is given by Mr. J. F. Horne, then Director of Forests and Botanical Gardens in Mauritius. In describing canes imported into Mauritius he wrote: "Two plants were found, one of which, while producing striped canes from one eye, produced green canes from another eye, both of which eyes belonged to the same piece of cane, while the second plant 


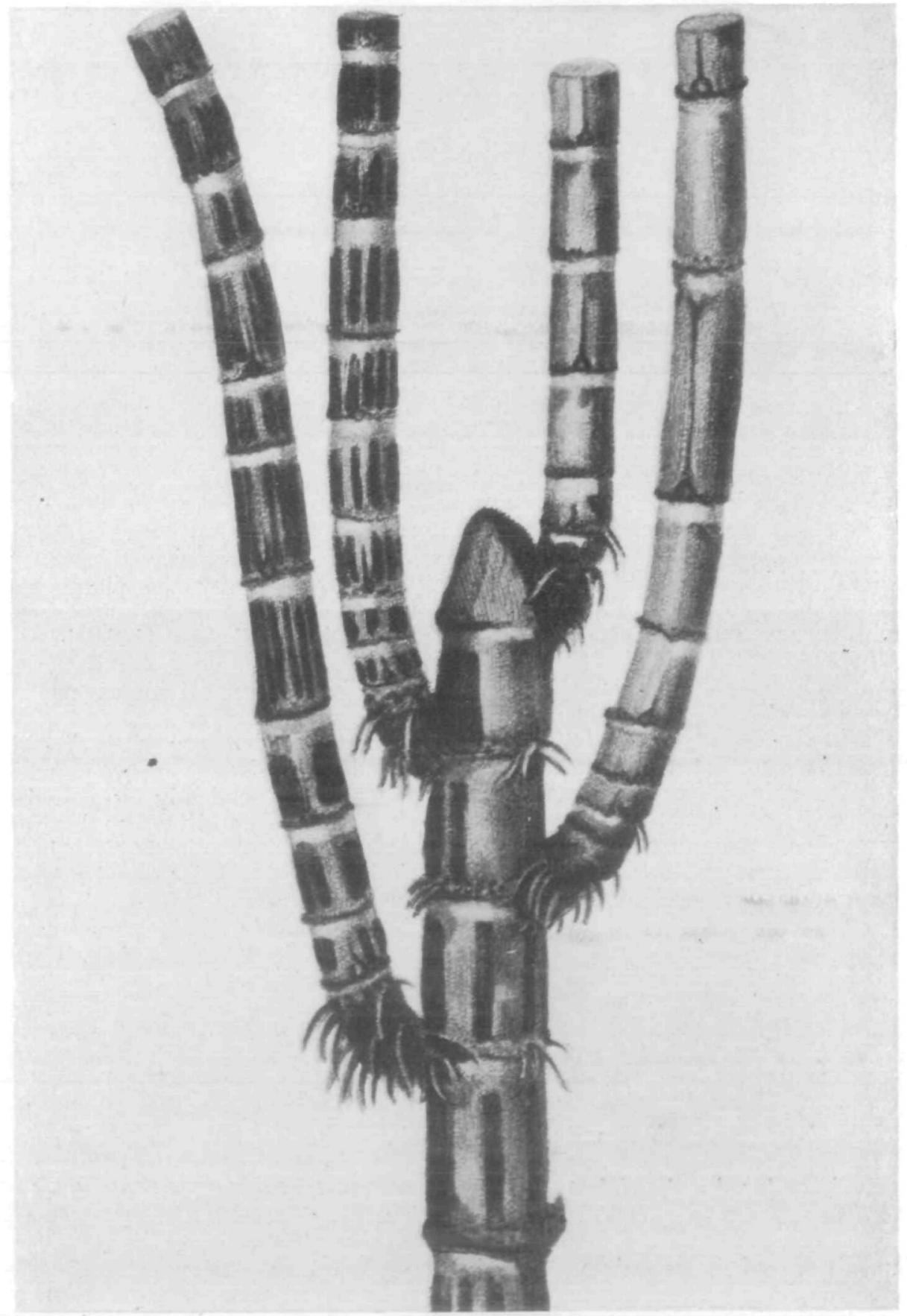

Bud variation in sugar cane found on the Kirton plantation, Barbados. From West Indian Bulletin, Vol. 2, No.3. (Fig. 16.) 
produced both striped and green canes from one and the same eye."

A very similar observation was made by Melmoth $\mathrm{Hall}^{2}$ a little later. $\mathrm{He}$ wrote: "I have in one instance seen no less than three distinct canes springing from one stool of the ribbon variety, one entirely yellow, one entirely green, the other being the usual ribbon cane; while from other stools in the same field I found canes either of a uniform green, purple or purplish-brown; all the rest spring from the same ribbon cane root, being striped in the usual way."

Mr. Deerr, writing in 1910, said that for generations the Louzier (Otaheite) cane, known under several names in different sections, had produced a very large proportion of the world's supply of sugar cane combining the characteristics of heavy tonnage, sweet and pure juice, and low fiber content. M. Auguste Villele, of Mauritius, thus described the origin of this variety in a letter to Mr. Deerr: "In 1868 or 1869 M. Lavignac introduced into Mauritius several varieties of cane from New Caledonia, among which was the Mignonne, a red and green striped variety. This cane was noticed by $M$. Louzier to throw sports and from a vellow sport the Louzier was developed, being the standard cane of Mauritius for many years."

The Louzier cane traveled from Mauritius to other districts and is not to be distinguished from the Yellow Otaheite cane of Cuba and Java, or from varieties grown under other names in several sugar-cane districts. $\mathrm{Mr}$. Deerr states that. having seen the Bourbon, the Lahaina, and the Louzier growing on a large scale in Demerara, Hawaii. and Mauritius, he has no hesitation in saying that they are indistinguishable. Stubbs ${ }^{s}$ and Harrison and Tenman ${ }^{4}$ also considered these varieties identical. It is then reasonable to sup- pose that the Lahaina and Bourbon canes, although introduced into Hawaii and the West Indies as self-colored canes, were originally in Otaheite sports from the cane introduced into Mauritius in 1868 or 1869 under the name Mignonne, and that in Otaheite the latter was cultivated as a separate cane.

Assuming the identity of the Louzier with the Otaheite and Lahaina canes as described above, and remembering the origin of the first mentioned, it is also probable that the other two originated in the same way but, having been introduced at early dates as self-colored canes, no suspicion of their origin arose. The Louzier cane also is known to throw a striped sport indistinguishable from the Mignonne from which the Louzier arose, and this cane in turn throws self-colored sports, thus completing the cycle through striped cane. self-colored cane, to striped cane again. although it is impossible to state which was the original type.

In December, 1890, Mr. J. F. Horne wrote the Director of the Royal Gardens at Kew as follows: "Of new varieties originating as bud sports we have eight or nine in Mauritius alone; some of them are very fine canes and they are extensively planted. Most of them are hardier than their parents and they yield more sugar. They are mostly obtained from new canes recently introduced. The sudden change of climate, soil, and other circumstances cause them to be thrown off. More of then might be obtained if the planters were more observing than they are and closely followed the cane cutters throughout their fields. As things are. a new variety is only observed should it chance to spring up in an outside row."

In the early nineties the Striped Tanna canes. Unrler th name of Yelcolor) was brought to Mauritius, and it was frequently observed to throw sports whence have come the White

\footnotetext{
2 The magazine Sugar Cane, No. 64.

${ }^{3}$ Dr. IV. Stubos, Sugar Canc, 1897. p. 66.

1 The' magazine Sugar Canc. No. 273.

"Kew Bulletin, 1891.
} 


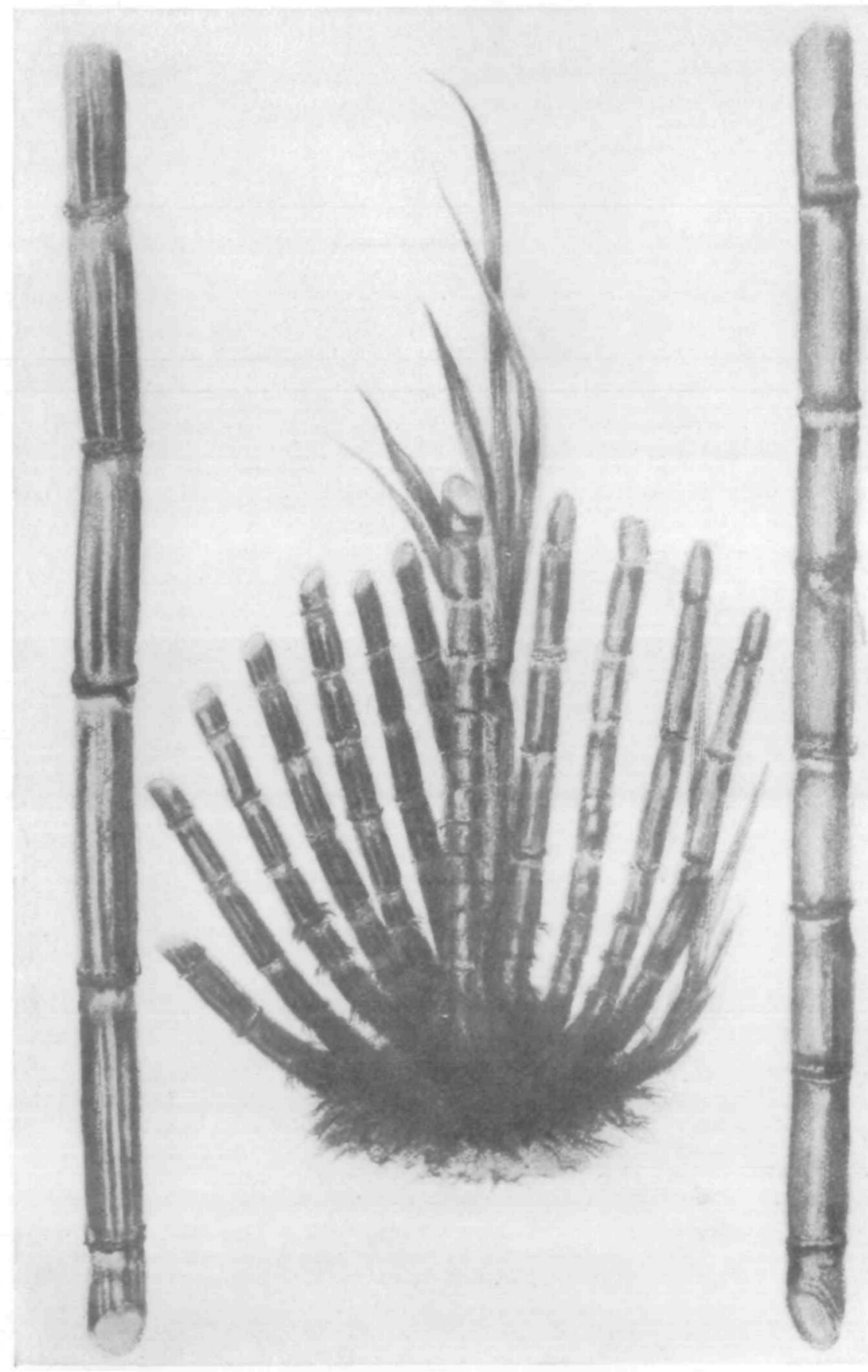

Stool of Red Ribbon (Striped Cheribon) sugar cane showing stalks of the Burke or White Cheribon variety appearing as a bud variation. Found by Mr. S. B. Kirton, owner of the Arthur Seat plantation, Barbados, in 1900. From West Indian Bulletin, Vol._2, No. 3. (Fig. 17.) 
(yellow color) and Black (purple color) Tanna canes. Under the name of Yellow Caledonia the White Tanna in 1910 formed the major portion of the unirrigated plantings in the Hawaiian Islands, as Malabar it was the favorite cane of Fiji, and as White Tanna it covered extensive areas in Mauritius. All three of the Tanna canes were also cultivated on a large scale in Australia.

Mr. James Clarke of North Queensland reported that the first instance of bud variation that he noticed was in New South Wales, where he had charge of a large sugar plantation. Having planted with his own hands some of the Striped Tanna cane in an endeavor to establish there a variety resistant to the "gumming" disease, he noticed when cutting the canes that some of them were entirely yellow and some purple without stripes. One stalk was found with the three lower joints striped like Striped Tanna and the upper portion of the stalk unstriped and completely yellow. The yellow and the purple canes were planted separately, as were the joints from the stalk that was partly striped and partly yellow, and in each case the resulting canes were true to the color of the cuttings planted.

The following experiment ${ }^{b}$ is reported from Louisiana: "As an illustration of bud variation, some stalks of cane, partly white and partly purple, were selected from the field of Soniat Bros., Tchoupitoulas plantation. They were called bastard canes. These stalks were planted as follows: First row, the entire stalk; second row, the white joints; third row, the colored joints. At the end of the season four distinct canes, as far as color could direct us, were obtained. Types of the four new varieties were selected and separately planted and the next year were found to be nearly pure. Selection and separate plantings have been made each year since. These canes have been named as follows: First, a white cane, No. 29, Soniat; second, a light striped cane, No. 59, Nicholls; third, a light purple cane, No. 64, Bird; fourth, a dark striped cane, No. 65, Garig. The yield and analyses of these canes have been annually made. They, except the white, are entirely different from any other cane in our collection."

An interesting bud variation (Fig. 1) was forwarded by the Hon. F. J. Clarke from Kirton plantation in Barbados to the West Indian Department of Agriculture and was exhibited by Dr. Morris, the Commissioner of Agriculture. at a meeting of the Barbados Agricultural Society in April, 1899. The specimen was a ribbon cane with very pronounced stripes on the main stem. Four successive joints had thrown off shoots, the first and third of which were striped with red like the parent cane, while the second and fourth were unstriped yellow canes. The resulting appearance was a striped parent cane bearing two striped shoots on one side and two unstriped shoots on the other side.

In March, 1900, Mr. S. B. Kirton, proprietor of the Arthur Seat plantation, Barbados, observed several stools of cane showing bud variation growing in the outside row of a field on his estate. From a common base sprang red striped canes on one side and pale yellow unstriped canes on the other side (Fig. 2). An examination of five clumps in which the phenomenon was noticed gave the following figures:

$\begin{array}{lccc} & \text { Slool } & \begin{array}{c}\text { White } \\ \text { canes }\end{array} & \begin{array}{c}\text { Red slriped } \\ \text { cantes }\end{array} \\ 1 . & \ldots \ldots \ldots & 6 & 6 \\ 2 . & \ldots \ldots \ldots & 9 & 6 \\ 3 \ldots & \ldots \ldots \ldots & 6 & 4 \\ 4 \ldots \ldots \ldots & 5 & 6 \\ 5 \ldots \ldots \ldots \ldots \ldots & 1 & 16\end{array}$

The cane originally planted was determined in each case to have been Red Ribbon (Striped Cheribon, yellow and blood red color). In one clump which was examined carefully it was found that a bud of the striped cane which was planted had produced a white cane which in turn produced a ribbon cane from a bud below the surface of the ground. The white canes were identical 
with the Burke variety (White Cheribon, yellow-violet color).

Subsequent to these -investigations Mr. James Clarke, of North Queensland, recorded the following instances of bud variation in a letter to Prof. J. B. Harrison, of the West Indian Department of Agriculture. In cutting Striped Singapore canes (Striped Cheribon) a short time previous he had noticed what appeared to be ripe, yellow Rappoe canes (Burke or White Cheribon) growing out of the middle of the Striped Singapore stools. Some stalks were found with purple stripes on a few of the lower joints, while the upper part of the stalk was of a uniform yellow color. Careful search showed that the canes planted had really been of the Striped variety. To make sure that the yellow canes growing from the center of the Striped Singapore stools were true sports, a stool of mixed canes was dug and sliced through the center. This showed that the striped canes were the parents of the yellow sports which had sprung from them.

There seems no reason to doubt that the White and Black Cheribon canes originated as variations from the Striped Cheribon, and they are repeatedly found appearing as sports of that variety. These canes have been introduced into nearly all cane-growing districts, and as sugar producers they are equal in value to the Otaheite.

It is important to note that when a striped cane throws sports two varieties arise, one light colored and one dark colored, and that almost always the light-colored and the dark-colored canes arising from any one variety are identical. Thus almost every light-colored sport from a Striped Tanna cane is a White Tanna, and nearly every darkcolored sport from a Striped Tanna is a Black Tanna.

\section{VARIATIONS FROM SELF-COLORED VARIETIES}

Sporting from self-colored canes has been less frequently observed than from striped canes, but some self-colored canes have been known to give rise to two distinct striped bud variations. In
Mauritius the Louzier (yellow color) has been known to throw two distinct sports, one a cane identical with the Mignonne (red and green striped), the parent of the Louzier, and the other the Horne (irregularly striped red, green and yellow). Mr. Deerr also observed similar sports springing from the Otaheite cane under the names of Bourbon and Lahaina in Demerara and Hawaii.

The Horne cane just mentioned is of especial interest as its appearance was one of the earliest, if not the earliest, recorded instance of a striped cane originating from a self-colored one. It was first found by Mr. J. F. Horne springing from a plant of the Louzier variety and has been grown on the plantation scale in Mauritius. A cane exactly similar to the Horne has been observed several times in Bourbon (Louzier or Otaheite)' fields in Demerara.

The Green Rose Ribbon cane is a green and yellowish-pink striped variety which originated as a sport of the Otaheite or Louzier and is grown with success in Australia.

Another instance of a bud variation of this same character was observed in the Hawaiian Islands by Mr. E. W. Broadbent, who found a green and yellow ribbon cane springing from the White Tanna. In this case the sport was quite distinct from the Striped Tanna, the parent of the White Tanna.

The Cavangerie cane, one of the standard varieties of the world, is extensively cultivated in Mauritius under the name Port Mackay. It is claret colored, with an inconspicuous but clearly defined deep green stripe. In Mauritius this variety has given rise to a black cane called the Port Mackay Noir.

Among the canes introduced into Mauritius from New Caledonia was a striped one originally known as Tsimbec, which is striped red and yellow. From it several sports have arisen, one of which, yellowish-red in color, is known as Iscambine Rouge and is grown on the plantation scale.

In Hawaii a variety called the Striped Tip (dark red and pinkish-green color), 
of uncertain origin, has given rise to the Yellow Tip (light green becoming yellow at maturity).

\section{SUMMARY}

These scaltering instances of bud variations may be briefly summarized as follows:

Bud variations in the sugar cane are quite common and have been recorded in Louisiana, the West Indies, Mauritius, Hawaii and Australia.

The difference between mother plants and sports is often as great as between recognized varieties.
Bud varieties have been noticed as

1. Differently colored side shoots from one cane.

2. Dillesently colored canes in one stool growing from a single piece of planted cane.

3. A stalk with some joints striped and some unstriped.

4. Strains showing differences in hardiness.

5. Strains showing differences in sugar content.

Plants grown from cuttings of the bud sports tend to reproduce true to the character of the sports.

\section{Better Dairying by Bull Associations-Joint Use of Good Sires Improves Herds}

Dairymen who would like to use pure-bred bulls to improve their herds but who cannot afford to purchase such animals should investigate the advantages of a coöperative bull association.

These organizations are formed by farmers for the joint ownership, use, and exchange of pure-bred bulls. The purchase price and cost of maintenance are distributed according to the number of cows owned by each member, thereby giving the dairyman an opportunity to build up his herd at a minimum expense. The organization also helps its members to market dairy stock and dairy products, to fight contagious diseases of cattle intelligently, and in other ways to assist in improving the dairy industry. Farmers' Bulletin 993, recently issued by the United States Department of Agriculture, gives directions for the organization and operation of bull organizations, together with constitution and by-laws necessary for such an organization.

The typical coöperative bull association, as recommended by the dairy specialists of the department, is composed of from fifteen to thirty farmers who jointly own five bulls. The territory in which these farmers live is divided into five "breeding blocks," one bull being assigned to each block.

In a survey conducted by the depart- ment on 1,219 farms in eight districts in Iowa, Minnesota, and Massachusetts, in which there were no associations, it was found that there were 817 bulls, having an average value of $\$ 76$. Had the owners of these cheap bulls been properly organized, the same investment would have purchased the necessary bulls of an average value of $\$ 283$. In one association having more than 100 members the original cost of good purebred bulls to each member was only $\$ 23$. When questioned regarding the value of coopperative bull associations, 150 farmers in Maryland, Michigan and Minnesota estimated that the use of bulls belonging to the organization increased the value of the offspring in the first generation from $30 \%$ to $80 \%$, with an average of $65 \%$.

\section{SUCCESS DEMANDS CARE}

The selection of the bulls for an association is one of the most important considerations. A good pure-bred bull will make rapid and marked improvement in the herds, and the association interest increases in proportion to the improvement obtained. If a poor dairy bull is used, the milk production of the members' herds is sometimes reduced, the interest is lessened, and these conditions may lead to the breaking up of the association.

\footnotetext{
${ }^{1}$ Weekly News Letter, U. S. Department of Agriculture.
} 